\title{
Short interference RNA introduced into cultured cells with diagnostic ultrasound
}

\author{
MINORU TOMIZAWA $^{1}$, FUMINOBU SHINOZAKI ${ }^{2}$, TAKAO SUGIYAMA ${ }^{3}$, \\ SHIGENORI YAMAMOTO ${ }^{4}$, MAKOTO SUEISHI $^{3}$ and TAKANOBU YOSHIDA ${ }^{5}$
}

\author{
Departments of ${ }^{1}$ Gastroenterology, ${ }^{2}$ Radiology, ${ }^{3}$ Rheumatology, ${ }^{4}$ Pediatrics, and ${ }^{5}$ Internal Medicine, National \\ Hospital Organization Shimoshizu Hospital, 934-5 Shikawatashi, Yotsukaido City, Chiba 284-0003, Japan
}

Received August 24, 2011; Accepted September 26, 2011

DOI: $10.3892 / o r .2011 .1506$

\begin{abstract}
Diagnostic ultrasound (US) is safe. Short interference (si) RNA of Frizzled (Fz)-9 suppresses proliferation of hepatocellular carcinoma cells. siRNA was introduced into Hep3B cells, a human hepatocellular carcinoma cell line, with transfection or US upward to culture plates at mechanical index $(\mathrm{MI})=0.4$ or 0.8 . siRNA of Fz9 was introduced for Western blot analysis and cell proliferation assay. siRNA of Fz9 suppressed cell proliferation to $32.8 \pm 13.6 \%$ at $200 \mathrm{nM}$ $(\mathrm{P}<0.0001)$ with transfection. With US, cell proliferation decreased to $36.9 \pm 15.1 \%$ at $200 \mathrm{nM}(\mathrm{P}=0.039)$ at 0.4 of $\mathrm{MI}$ while $49.2 \pm 12.0 \%$ at $200 \mathrm{nM}(\mathrm{P}=0.041)$ at $\mathrm{MI}=0.8$. Western blot analysis showed that $200 \mathrm{nM}$ of siRNA decreased the expression of $\mathrm{Fz} 9$ with $\mathrm{US}$ at $\mathrm{MI}=0.4$ and $\mathrm{MI}=0.8$. No change was seen in cell proliferation between transfection and US. siRNA was introduced into cultured cells and functioned with US.
\end{abstract}

\section{Introduction}

Methods of introducing therapeutic genes are important to obtain satisfactory anti-cancer effects in the treatment of cancer. Viral vectors are potent in gene delivery but can be hazardous. Non-viral delivery is safe but its efficiency is disappointingly low in introducing genes. Plasmid DNA was successfully introduced into cultured cells with a sonicator (1). Irradiation of low output intensity ultrasound increases the effects of introduction of genes into tissues (2). The biological effects of ultrasound are categorized as thermal mechanism and non-thermal (3). Non-thermal effects are caused by cavitation, mechanical perturbation in the vicinity of bubbles, leading to membrane poration (4). This phenomenon, sonoporation,

Correspondence to: Dr Minoru Tomizawa, Department of Gastroenterology, National Hospital Organization Shimoshizu Hospital, 934-5 Shikawatashi, Yotsukaido City, Chiba 284-0003, Japan

E-mail: nihminor-cib@umin.ac.jp

Key words: ultrasonography, WNT signaling pathway, MTS assay, frizzled-9, luciferase assay is a gene delivery method that is expected as a potential new method of gene therapy as evidenced in a murine model (5). Collapse of cavitation can generate small transient holes on a cell membrane and induces cell membrane permeabilization $(6,7)$. Substrates, such as DNA, can pass through the hole in the cell membrane.

In addition to conventional treatment, molecular therapy to hepatocellular carcinoma (HCC) is currently under clinically investigation (8). To develop a new molecular therapy, analysis of signal transduction is essential (9). The Wnt signaling pathway is involved in abnormal cell growth and cancer (10). Fzizzled $(\mathrm{Fz})$ is a cell surface receptor that mediates actions of Wnt ligands, and 10 members of the Frizzled family have been identified (11). Fz9 is not expressed in normal liver, but expressed in HCC and hepatoblastoma cell lines examined (12). Short interference (si) RNA of Fz9 suppresses proliferation of HCC cell lines decreasing the expression of cyclin D1 (12). Suppression of Fz9 would be an ideal target of a new molecular therapy of HCC since it would not cause any adverse events to surrounding normal liver tissues.

To increase the efficiency of gene delivery, cells can be damaged by intense standing waves and significant temperature increases (13). Safe methods of gene transfer would be desirable for treatment. Diagnostic US is relatively safe and capable of real-time monitoring of the irradiated fields. Thus, we used diagnostic ultrasound (US) to introduce siRNA to cultured HCC cells.

\section{Materials and methods}

Cell culture. Hep3B (RIKEN BioResource Center, Tsukuba, Japan), a hepatocellular carcinoma cell line, were cultured in Dulbecco's minimum essential medium (DMEM) (Sigma, St. Louis, MO) supplemented with $10 \%$ fetal bovine serum (FBS) (Invitrogen, Carlsbad, CA) in $5 \%$ carbon dioxide at $37^{\circ} \mathrm{C}$. Twenty-four-well plates (Asahi Techno Glass, Funabashi, Japan) and 96-well plates (Asahi Techno Glass) were used for luciferase assay and Western blot analysis, and cell proliferation assay, respectively.

Irradiation with US. Cultured cells were irradiated with a linear probe at the frequency of $8 \mathrm{MHz}$ at the mechanical index $(\mathrm{MI})=0.4$ (the lowest in our machine) or 0.8 (the highest) 


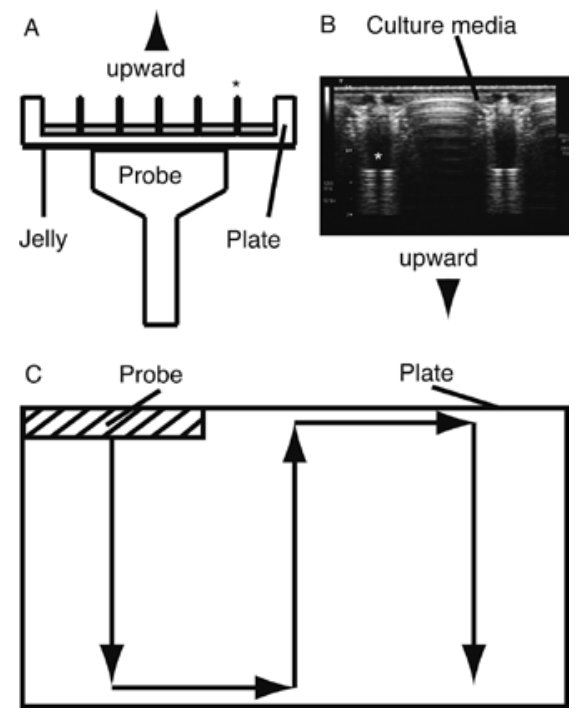

Figure 1. Methods of irradiation with US. A linear probe was touched upward to the surface of the bottom of a plate through ultrasound jelly (A). A representative image obtained on the US when aimed at a 24-well plate (B). (C) Depicts a schematic view from the beneath. The probe was moved slowly for 5 min. Gray box, culture media; hatched box, probe; arrowhead, direction to up; arrow, scanning direction; asterisk, plastic wall between wells.

using SSA-700A (Toshiba Medical Systems Corp., Ohtawara, Japan). The probe was touched upward to the bottom of a plate through ultrasound jelly (Fig. 1A). The irradiated field was observed through the display (Fig. 1B). The probe was scanned slowly to irradiate all fields for $5 \mathrm{~min}$ (Fig. 1C).

Introduction of fluorescein-labeled double-strand RNA. When cells reached $70 \%$ confluency fluorescein-labeled doublestrand (ds)RNA (Invitrogen) was introduced into cells at the concentration of $200 \mathrm{nM}$ by transfection with Lipofectamine 2000 (Invitrogen) or US. After $48 \mathrm{~h}$, cells were observed under fluorescence microscope (Carl Zeiss Microimaging Japan, Tokyo, Japan).

Luciferase assay. When cells reached $70 \%$ confluency, they were transfected with $0.46 \mu \mathrm{g}$ of pGL3-control (Promega, Madison, WI) together with $0.046 \mu \mathrm{g}$ of pRL-TK (Promega) an internal control vector, with Lipofectin (Invitrogen) to obtain the same level of the luciferase activity. After $5 \mathrm{~h}$, cells were transfected with siRNA of firefly luciferase (Nippon Gene Co., Ltd., Tokyo, Japan) using Lipofectamine 2000 or irradiated with US. After $48 \mathrm{~h}$, the transcriptional activity was measured with a dual luciferase reporter assay system (Promega) Mock was applied as no siRNA in the media. Negative control siRNA (Invitrogen) was used as a negative control. The relative luciferase activity was calculated as firefly luciferase activity divided by renilla luciferase activity.

Cell proliferation assay. The next day after the cell spread at 1000/well, siRNA of Fz9 (Invitrogen) was introduced into cells with Lipofectamine 2000 or US. Mock was applied as no siRNA in the media. The negative control siRNA (Invitrogen) was used. After $72 \mathrm{~h}$, 3-(4,5-dimethylthiazol-2-yl)-5-(3-carboxymethoxyphenyl)-
Fluorescein-labeled ds RNA
$(-)$

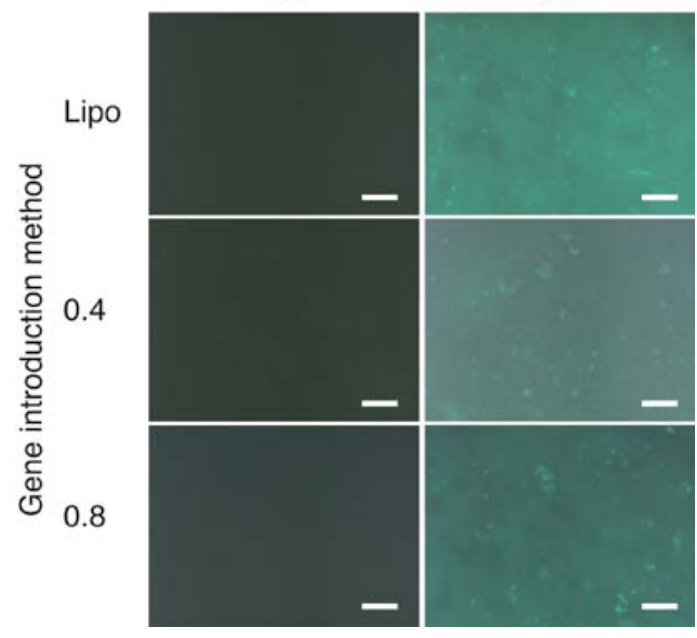

Figure 2. Introduction of fluorescein-labeled double-strand RNA with US. Fluorescein-labeled double-strand (ds)RNA was introduced into Hep3B cells with transfection with Lipofectamine 2000 (Lipo), or US at the mechanical index $(\mathrm{MI})=0.4(0.4)$ or $0.8(0.8)$ with $(+)$ or without $(-)$ fluorescein-labeled dsRNA at $200 \mathrm{nM}$. Signals were observed in trasfected cells with Lipofectamine 2000 as well as irradiated with US. Lipo, tranctection with Lipofectamine 2000; 0.4 , irradiation with US at the $\mathrm{MI}=0.4$; and 0.8 , irradiation with US at the MI=0.8. (-), without fluorescein-labeled dsRNA; (+), with fluorescein-labeled dsRNA. Original magnification, x20; scale bar, $100 \mu \mathrm{m}$.

2-(4-sulfophenyl)-2H-tetrazolium inner salt (MTS) assay was performed following the instructions (Promega).

Western blot analysis. Forty-eight hours after introduction of siRNA of Fz9 (Invitrogen) with transfection or US, protein was isolated and $10 \mu \mathrm{g}$ samples were subjected to sodium dodecyl sulphate polyacylamide gel electrophoresis, and transferred to a nylon filter. The primary antibodies were rabbit polyclonal anti-Fz9 antibody (Bioworld Technology, Inc., St. Louis Park, MN), or mouse monoclonal anti-tubulin- $\alpha$ antibody (Lab Vision, Fremont, CA). The secondary antibodies were horseradish peroxidase (HRP)-linked anti-rabbit antibody (GE Healthcare, Buckinghamshire, UK) or HRP-linked antimouse antibody (GE Healthcare). Dilutions were 1:500 for primary antibodies, and 1:1000 for secondary antibodies. The filter was reprobed with anti-tubulin- $\alpha$ antibody. The specific antigen-antibody complexes were visualized by enhanced chemiluminescence (GE Healthcare).

Statistical analysis. One-factor analysis of variance (ANOVA) was applied as statistical analysis with JMP5.0J (SAS Institute Japan, Tokyo, Japan). $\mathrm{P}<0.05$ was accepted as statistically significant.

\section{Results}

After transfection or irradiation with US, the signal was observed under fluorescence microscope (Fig. 2). Although the numbers were smaller than transfection, the signals were clearly seen in cells irradiated with US at both MI $=0.4$ and 0.8 .

siRNA of firefly luciferase was introduced into Hep3B cells. With transfection, relative luciferase activity decreased 

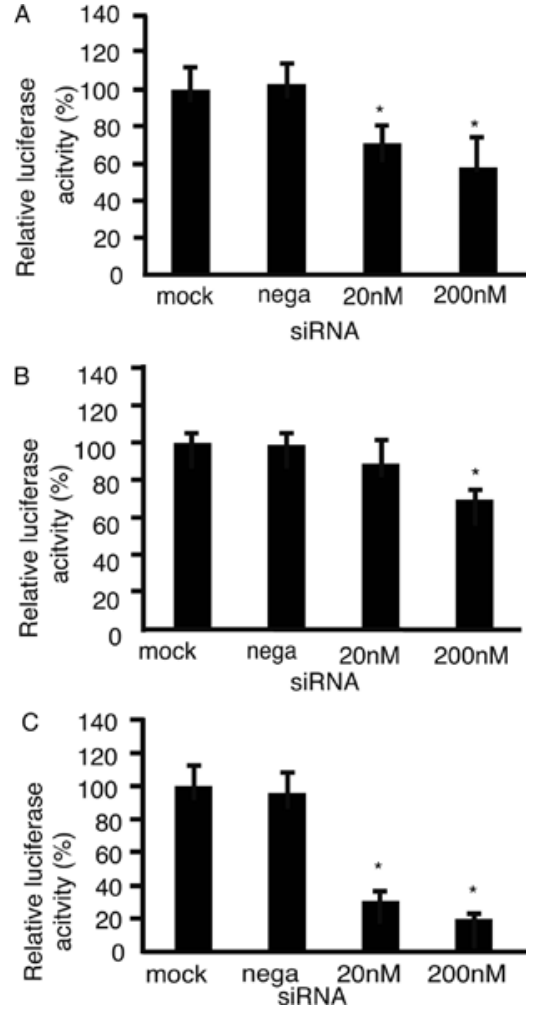

Figure 3. Luciferase assay. siRNA of firefly luciferase were introduced into Hep3 cells with transfection with Lipofectamine 2000 (A) or irradiation with US at mechanical index $=0.4$ (B) or $0.8(\mathrm{C}), 5 \mathrm{~h}$ after transfection of pGL3 control vector. After $48 \mathrm{~h}$, they were subjected to luciferase assay. Mock, no addition of siRNA; nega, $200 \mathrm{nM}$ of negative control siRNA. " $\mathrm{P}<0.05$ (one-factor ANOVA), $\mathrm{n}=3$.
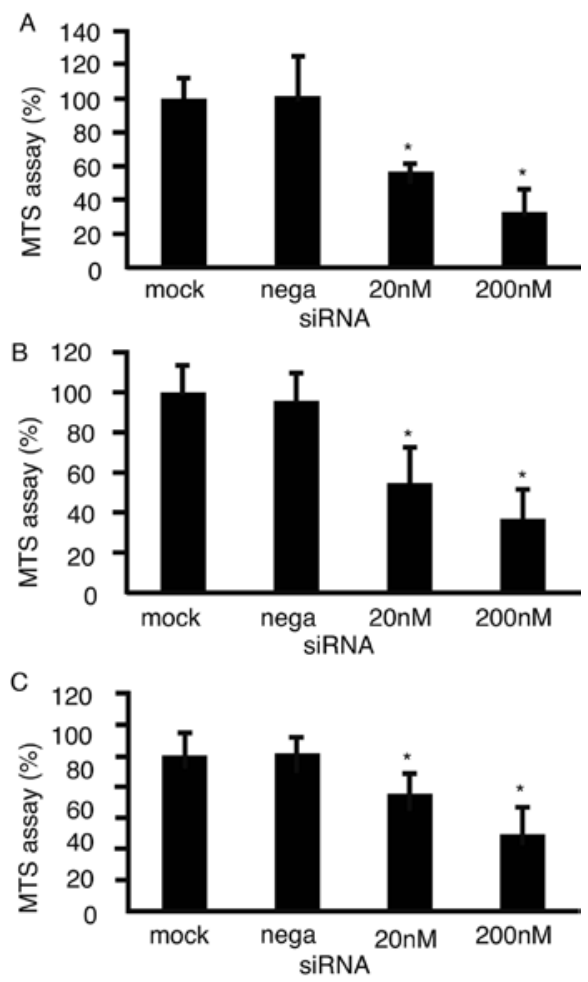

Figure 4. Cell proliferation assay. Cell proliferation was suppressed with transfection (A). With irradiation with US, cell proliferation was suppressed at both the MI $=0.4(\mathrm{~B})$ and $0.8(\mathrm{C})$. Mock, without siRNA; nega, negative control of siRNA; $20 \mathrm{nM}$, addition of siRNA of Fz9 at $20 \mathrm{nM} ; 200 \mathrm{nM}$, addition of siRNA of Fz9 at $200 \mathrm{nM}$. ${ }^{*} \mathrm{P}<0.05$ (one-factor ANOVA), n=3.

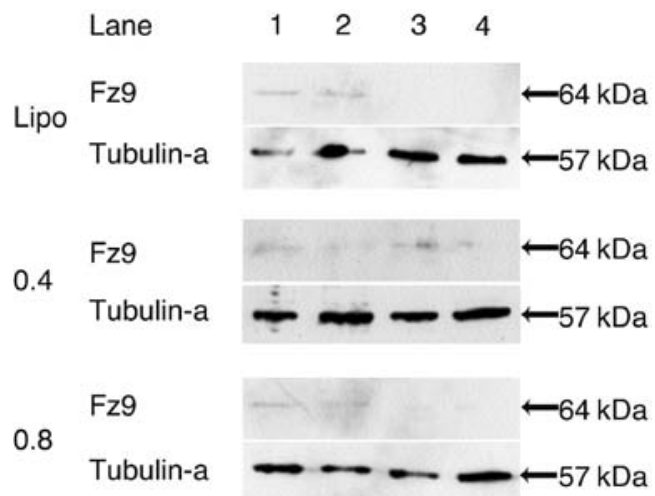

Figure 5. Western blot analysis. Protein was isolated after transfection or irradiation with US, and subjected to Western blot analysis. Lane 1, mock (without siRNA); 2, negative control of siRNA; 3, addition of siRNA of Fz9 at $20 \mathrm{nM}$; 4, addition of siRNA of Fz9 at $200 \mathrm{nM}$. Lipo, transfection with Lipofectamine 2000; 0.4 and 0.8, mechanical index $=0.4$ and 0.8 .

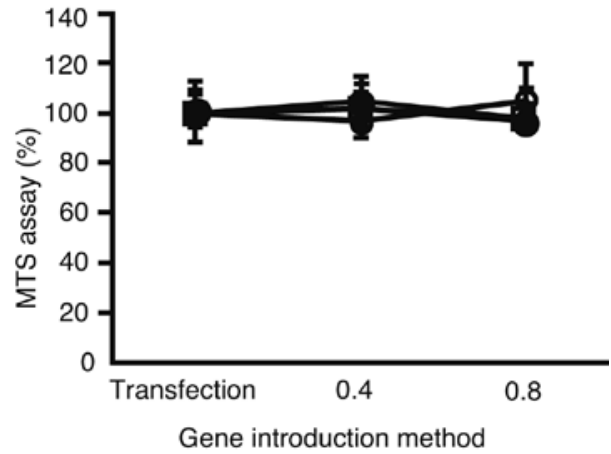

Figure 6. Cell proliferation assay. To analyze the damage to the cultured cells with US, cell proliferation was analyzed after $72 \mathrm{~h}$ culture with cells in media only (O), mock (without siRNA) () or $200 \mathrm{nM}$ of negative control of siRNA (•). 0.4 and 0.8 , mechanical index $=0.4$ and 0.8 .

to $71 \pm 9.6 \%$ (mean \pm standard deviation) $(\mathrm{P}=0.015)$ at $20 \mathrm{nM}$ and $57.9 \pm 17 \%(\mathrm{P}=0.02)$ at $200 \mathrm{nM}$ (Fig. 3A). With US at $\mathrm{MI}=0.4$, relative luciferase activity decreased to $69.6 \pm 5.1 \%$ at $200 \mathrm{nM}(\mathrm{P}=0.014)$ (Fig. 3B). At $\mathrm{MI}=0.8$, relative luciferase activity significantly decreased to $30.1 \pm 5.9 \%(\mathrm{P}=0.021)$ at $20 \mathrm{nM}$ and $19.2 \pm 3.1 \%(\mathrm{P}=0.0055)$ at $200 \mathrm{nM}$ (Fig. 3C).

SiRNA of Fz9 suppressed cell proliferation when transfected with Lipofectamine 2000 (Fig. 4A) to $56.8 \pm 4.8 \%$ $(\mathrm{P}=0.013)$ at $20 \mathrm{nM}$ and $32.8 \pm 13.6 \%$ at $200 \mathrm{nM}(\mathrm{P}<0.0001)$. When irradiated with US, cell proliferation was significantly suppressed by siRNA of $\mathrm{Fz} 9$ at $\mathrm{MI}=0.4$ to $54.8 \pm 17.8 \%$ $(\mathrm{P}=0.022)$ at $20 \mathrm{nM}$ and $36.9 \pm 15.1 \%$ at $200 \mathrm{nM}(\mathrm{P}=0.039)$ (Fig. 4B) as well as 0.8 to $75 \pm 4.8$ at $20 \mathrm{nM}(\mathrm{P}=0.047)$ and $49.2 \pm 12.0 \%$ at $200 \mathrm{nM}(\mathrm{P}=0.041)$ (Fig. $4 \mathrm{C})$.

When transfected with siRNA of Fz9, the expression of Fz9 decreased at 20 and $200 \mathrm{nM}$ (Fig. 5). The expression of Fz9 decreased when irradiated with $200 \mathrm{nM}$ of siRNA of Fz9 at $\mathrm{MI}=0.4$. At $\mathrm{MI}=0.8$, the expression of $\mathrm{Fz} 9$ decreased at 20 as well as $200 \mathrm{nM}$. These results clearly indicated that siRNA suppressed protein expression introduced into cells when irradiated with ultrasound.

The effect of US on cell proliferation was analyzed (Fig. 6). No change in cell proliferation was seen among transfection, 
US at MI $=0.4$, or MI $=0.8$ in cells under media only. The same trend was shown in mock and negative control. These data clearly indicated that US did not damage cells.

\section{Discussion}

siRNA is a novel tool for treatment of human diseases. Regarding clinical trials, siRNA has been applied to inherited skin disorder and cancer $(14,15)$. Because it is hard for naked siRNA to cross the cell membrane, special delivery methods have been developed, such as physical methods, hydrodynamic injection, mechanical massage, and electroporation (16). Hydrodynamic injection is based on rapid injection of much siRNA (17). Due to invasive nature, hydrodynamic injection and electroporation are mostly used for animal experiments. siRNA has been introduced into cells with sonoporation, a non-invasive method, and silenced the expression of green fluorescent protein (GFP) (18). In our expreriments, siRNA was successfully introduced into cultured cells with US. Our data, moreover, clearly showed that siRNA of Fz9 suppressed proliferation of Hep3B cells with US. Our study first presented anti-cancer effects with therapeutic siRNA introduced with US. Interestingly, siRNA to GFP silences the signal after intravenous injection to mice bearing GFP-expressing tumor cells (19). siRNA accumulates in the liver when administered in vivo (20). Taken together, application of siRNA would be one of suitable methods of molecular therapy to HCC. It would be expected that HCC could be introduced with therapeutic siRNA precisely through real-time monitoring. Moreover, US was safe since no cells were damaged as shown in Fig. 6. It would be safe to conclude that US is one of the potential methods for gene therapy with siRNA.

The mechanism of biophysical effects of ultrasound is categorized as cavitation, radiation and acoustic microstreaming (3). Among them, cavitation mostly has been under investigation. However, cavitation is unlikely to occur at lower than 0.7 of MI (21). In our experiments, siRNA was introduced and functioned at $\mathrm{MI}=0.8$. It was speculated that our MI was strong enough for cavitation. On the other hand, siRNA of luciferase silenced the expression of luciferase marginally at $\mathrm{MI}=0.4$ while suppressed the expression of $\mathrm{Fz} 9$ and showed significant anti-cancer effect. The mechanism of introduction of siRNA at $\mathrm{MI}=0.4$ was not clear. In fact, it is not fully known how molecules enter cells. Based on the literature, there are three candidate mechanisms for molecular uptake by ultrasound: active transport, passive transport and uptake through actively repairable wounds (3). The first is via endocytosis by surface receptors that could be up-regulated. The second is through nanometer pores in the membrane similar to those caused by electroporation. The third is through wounds in the membrane similar to those caused by physical stresses (22).

Our next step would be the application of siRNA with US in an animal model of cancer to validate the concept of using US in gene transfer in vivo.

\section{Acknowledgements}

This study was in part supported by Grant-in-Aid for Encouragement of Scientists (Grant no. 22931047) and Research Grant-in-Aid for Scientific Research (C) (Grant no. 23591002) from the Japan Society for the Promotion of Science (JSPS). The authors thank Professor Masaki Takiguchi and Dr Katsuro Iwase for microscopical analysis and fruitful discussions.

\section{References}

1. Fechheimer M, Boylan JF, Parker S, Sisken JE, Patel GL and Zimmer SG: Transfection of mammalian cells with plasmid DNA by scrape loading and sonication loading. Proc Natl Acad Sci USA 84: 8463-8467, 1987.

2. Tomizawa M, Ebara M, Saisho H, Sakiyama S and Tagawa M: Irradiation with ultrasound of low output intensity increased chemosensitivity of subcutaneous solid tumors to an anti-cancer agent. Cancer Lett 173: 31-35, 2001.

3. O'Brien WD Jr: Ultrasound-biophysics mechanisms. Prog Biophys Mol Biol 93: 212-255, 2007.

4. Miller DL, Pislaru SV and Greenleaf JE: Sonoporation: mechanical DNA delivery by ultrasonic cavitation. Somat Cell Mol Genet 27: 115-134, 2002.

5. Casey G, Cashman JP, Morrissey D, et al: Sonoporation mediated immunogene therapy of solid tumors. Ultrasound Med Biol 36: 430-440, 2010.

6. Tachibana $\mathrm{K}$ and Tachibana S: The use of ultrasound for drug delivery. Echocardiography 18: 323-328, 2001.

7. Koch S, Pohl P, Cobet U and Rainov NG: Ultrasound enhancement of liposome-mediated cell transfection is caused by cavitation effects. Ultrasound Med Biol 26: 897-903, 2000.

8. El-Serag HB, Marrero JA, Rudolph L and Reddy KR: Diagnosis and treatment of hepatocellular carcinoma. Gastroenterology 134: 1752-1763, 2008

9. Luo J, Solimini NL and Elledge SJ: Principles of cancer therapy: oncogene and non-oncogene addiction. Cell 136: 823-837, 2009

10. Katoh $M$ and Katoh M: WNT signaling pathway and stem cell signaling network. Clin Cancer Res 13: 4042-4045, 2007.

11. Wang HY, Liu T and Malbon CC: Structure-function analysis of Frizzleds. Cell Signal 18: 934-941, 2006.

12. Fujimoto T, Tomizawa M and Yokosuka O: siRNA of frizzled-9 suppresses proliferation and motility of hepatoma cells. Int $\mathrm{J}$ Oncol 35: 861-866, 2009.

13. Hassan MA, Buldakov MA, Ogawa R, et al: Modulation control over ultrasound-mediated gene delivery: evaluating the importance of standing waves. J Control Release 141: 70-76, 2010.

14. Leachman SA, Hickerson RP, Schwartz ME, et al: First-inhuman mutation-targeted siRNA phase $\mathrm{Ib}$ trial of an inherited skin disorder. Mol Ther 18: 442-446, 2010.

15. Davis ME, Zuckerman JE, Choi CH, et al: Evidence of RNAi in humans from systemically administered siRNA via targeted nanoparticles. Nature 464: 1067-1070, 2010.

16. Higuchi $\mathrm{Y}$, Kawakami S and Hashida M: Strategies for in vivo delivery of siRNAs: recent progress. BioDrugs 24: 195-205, 2010.

17. Liu F, Song Y and Liu D: Hydrodynamics-based transfection in animals by systemic administration of plasmid DNA. Gene Ther 6: 1258-1266, 1999.

18. Kinoshita M and Hynynen $\mathrm{K}$ : A novel method for the intracellular delivery of siRNA using microbubble-enhanced focused ultrasound. Biochem Biophys Res Commun 335: 393-399, 2005.

19. Medarova Z, Pham W, Farrar C, Petkova V and Moore A: In vivo imaging of siRNA delivery and silencing in tumors. Nat Med 13: 372-377, 2007.

20. Takakura Y, Mahato RI, Yoshida M, Kanamaru T and Hashida M: Uptake characteristics of oligonucleotides in the isolated rat liver perfusion system. Antisense Nucleic Acid Drug Dev 6: 177-183, 1996.

21. Forsberg F, Shi WT, Merritt CR, Dai Q, Solcova M and Goldberg BB: On the usefulness of the mechanical index displayed on clinical ultrasound scanners for predicting contrast microbubble destruction. J Ultrasound Med 24: 443-450, 2005.

22. Schlicher RK, Radhakrishna H, Tolentino TP, Apkarian RP, Zarnitsyn V and Prausnitz MR: Mechanism of intracellular delivery by acoustic cavitation. Ultrasound Med Biol 32: 915-924, 2006. 